EPiC Series in Engineering
Volume 3, 2018, Pages 1224-1231
HIC 2018. 13th International
Conference on Hydroinformatics

\title{
Modeling of Urban Flood in Xiamen Island, China
}

\author{
Jiahong $\mathrm{Liu}^{1,2^{*}}$, WeiWei Shao ${ }^{1}$, Chenyao Xiang ${ }^{1}$, Chao $\mathrm{Mei}^{1}$, and Zejin $\mathrm{Li}^{1}$ \\ ${ }^{1}$ State Key Laboratory of Simulation and Regulation of Water Cycle in River Basin, China of \\ Institute of Water Resources and Hydropower Research, Beijing 100038, China \\ ${ }^{2}$ Engineering and Technology Research Center for Water resources and Hydroecology of the \\ Ministry of Water Resources, Beijing 100038, China \\ liujh@iwhr.com, shaowwliwhr.com, meichaodiwhr.com, \\ xiangchenyao@foxmail.com, lizejin13@qq.com
}

\begin{abstract}
Rapid urbanization has greatly increased the impermeable surface in urban area, which led to serious urban flooding and waterlogging in China. There are more than 100 cities that suffered from urban flood every year since 2006, and more than 100 million citizens are involved in China. Urban flood mitigation is one of the most important issues for both water administration and city management agency. This paper simulated the urban flooding in Xiamen Island based on a hydrodynamic model coupled with hydrological model. The datasets of underlying surfaces were input to the model, including the terrain data, building plan, land use, etc. A typical rain pattern of 50 years return event were used for flood simulation. The results show that the main inundated areas (flooded depth more than $40 \mathrm{~cm}$ ) are located in three groups: south east to the Yundang Lake, around the Hubian Reservoir, along the Exhibition Road. The other inundated areas that less than $40 \mathrm{~cm}$ deep are scattered in the flat regions of Xiamen Island. The main inundated areas simulated are consistent with the point survey of urban flooding, which verifies that the suggest model is reasonable and useful for urban flood prediction.
\end{abstract}

\section{Introduction}

China is experiencing rapid urbanization (Montgomery, 2008), which induces many hydrological effects (J. Zhang X. S., 2014), such as rain-island effect (A. Kadari, 2011), increasing of runoff and urban flooding (Zheng Z, 2016). Urban flooding is now the most important problem not only in east monsoon regions of China, but also in some big cities in semi-arid regions in western China (J. Zhang

*Corresponding author: 1iujh@iwhr.com 
Y. W., 2016). Since 2006, there are more than 100 cities that suffered from urban flood. Urban flood is a comprehensive effect of various factors, including:

- Climate change, which leads to extreme weather events;

- Rain island effect, which increases the city's storm frequency and intensity;

- Expansion of build-up area, which encroaches the passage and storage space of flood;

- Impermeable surface, which changes the amount and process of surface runoff;

- Low drainage capacity, most of current drainage systems can't withstand 1-year rain event;

- Underground space development, the sunken infrastructures are prone to frequent floods;

- Superposition effect, the external flood and internal waterlogging happen to meet each other;

- Neglect management, capacity of drainage facilities decreases for inadequate maintenance.

The above factors have changed the hydrodynamic characteristics in urban area. It is necessary to simulate the rain-runoff, flooding and inundating, considering the complex underlying surfaces in urban area. Leandro (Leandro J, 2016) et al. considered the spatial heterogeneity of urban key features in urban hydrology flood modelling. Smith (Smith B K, 2013) et al. studied the spectrum of storm event hydrologic response in urban watersheds. There are many other researchers have done experiment, modeling, monitoring on urban flood, such as Ragab (Ragab R, 2003), Amaguchi (Amaguchi H, 2012), Thomas (Thomas C W, 2014), Ramier (Ramier D, 2011) et al. Few of them have done the coupled modeling of hydrology and hydraulics (Liu Jiahong W. H., 2014). This paper has coupled the hydrological and hydrodynamic module into an integrated urban flood model (Liu Jiahong M. C., 2017). The model is applied in Xiamen Island, which is the venue of BRICs summit in 2017, and also the first batch of Sponge City construction pilots of China (Jiahong Liu, 2016).

\section{Methodology}

The urban flood model consists of hydrological part and hydrodynamic part

Figure 1. The hydrological model classifies the urban underlying surface into four types: impermeable surface, semi-permeable surface, permeable surface and water surface. The four types of surface have different hydrological processes as to evapotranspiration, infiltration and storage (

Figure 1 for details). The runoff simulated by hydrological module is connected to hydrodynamic module step by step (timely) for every unit (spatially). Then the outputs of the hydrodynamic module are verified by point survey of urban flooding.

\subsection{Hydrological module}

The rain-runoff processes are simulated by the hydrological module according to different kinds of underlying surface. The hydrological processes are mainly classified into three groups:

evapotranspiration (ET), infiltration and storage. For impermeable surface, such as buildings and roads, there isn't infiltration process and the items of ET and storage limited. For permeable surface, such as green land, the items of ET, infiltration and storage are complete

Figure 1. This model takes account of six items of ET, which are leaf interception ET, soil ET, detention ET, water evaporation, plant transpiration and artificial evaporation (the ET enhanced by human activities); two items of infiltration, which are soil infiltration and deep percolation; and three items of storage, which are surface storage, soil storage and underground storage (storage facilities built by human beings). 


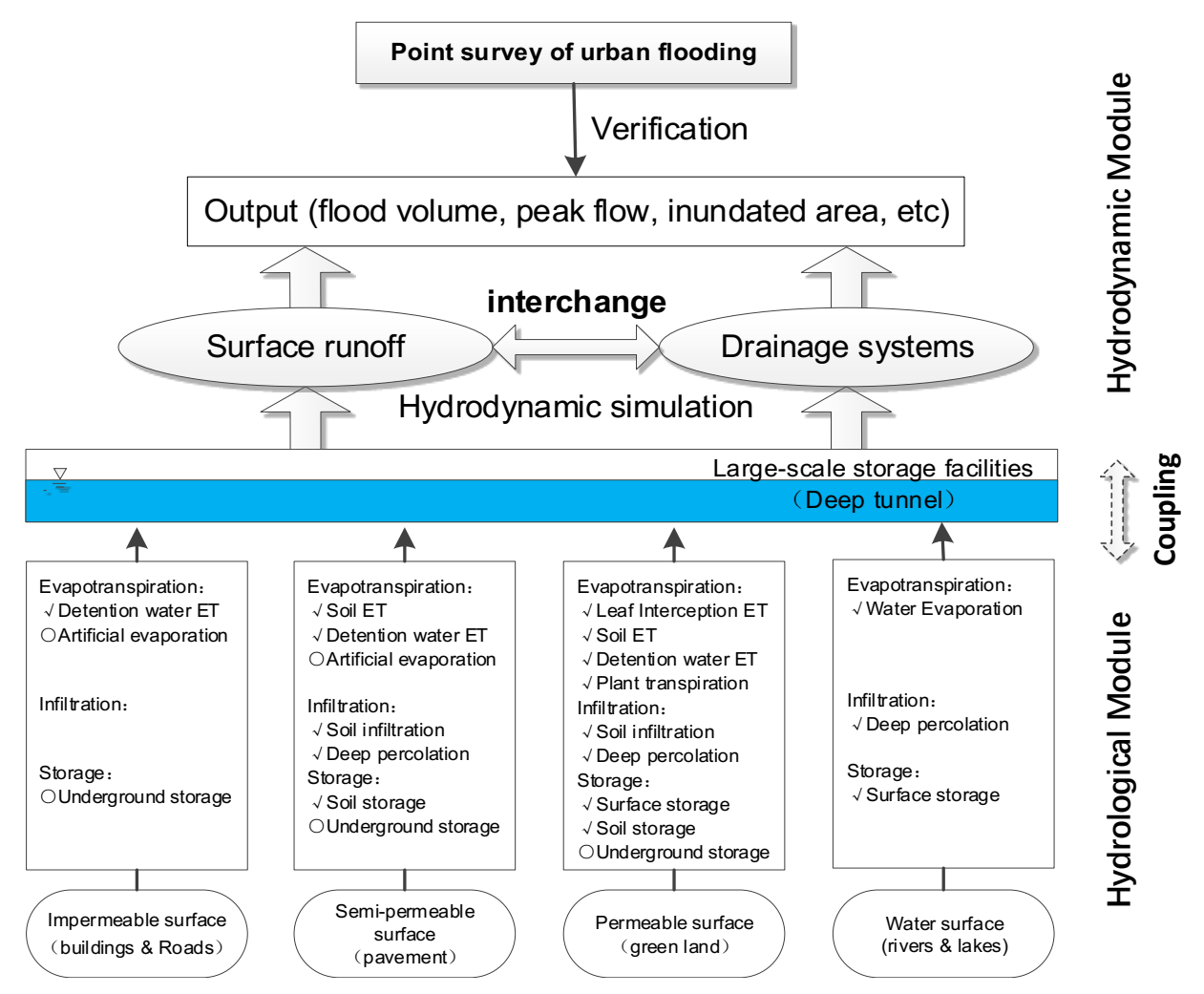

Figure 1: Framework of the urban flood model

\subsection{Hydrodynamic module}

The runoff and flooding on the land surface is simulated by using two-dimensional shallow water equations, which are derived from Navier-Stokes equations. Equation (1) is the continuity equation, and Equation (2) is the momentum equations.

$$
\begin{aligned}
& \frac{\partial h}{\partial t}+\frac{\partial q_{x}}{\partial x}+\frac{\partial q_{y}}{\partial y}=0 \\
& \left\{\begin{array}{l}
\frac{\partial q_{y}}{\partial t}+\frac{\partial\left(B q_{x} q_{y} / h\right)}{\partial x}+\frac{\partial\left(B q_{y}^{2} / h\right)}{\partial y}+g h \frac{\partial(h+z)}{\partial y}+\frac{g n^{2} q_{y} \sqrt{q_{x}^{2}+q_{y}^{2}}}{h^{7 / 3}}-V\left[\frac{\partial^{2} q_{y}}{\partial x^{2}}+2 \frac{\partial^{2} q_{y}}{\partial y^{2}}+\frac{\partial^{2} q_{x}}{\partial x \partial y}\right]=0 \\
\frac{\partial q_{x}}{\partial t}+\frac{\partial\left(B q_{x}^{2} / h\right)}{\partial x}+\frac{\partial\left(B q_{x} q_{y} / h\right)}{\partial y}+g h \frac{\partial(h+z)}{\partial x}+\frac{g n^{2} q_{x} \sqrt{q_{x}^{2}+q_{y}^{2}}}{h^{7 / 3}}-V\left[2 \frac{\partial^{2} q_{x}}{\partial x^{2}}+\frac{\partial^{2} q_{x}}{\partial y^{2}}+\frac{\partial^{2} q_{y}}{\partial x \partial y}\right]=0
\end{array}\right.
\end{aligned}
$$

where $q_{x}, q_{y}$ is discharge per unit width in $X, Y$ direction respectively; $h$ is water depth; $z$ is elevation; $[x, y, t]$ is $X, Y$ and time coordinate respectively; $B$ is Boussinesq coefficient; $g$ is gravity quota; $n$ is Manning roughness coefficient; $V$ is kinematic eddy viscosity.

\subsection{Numerical solution}

In this research, the hydrological modelling produces runoff yield for each grid, which adds to $h$ and then substitutes to hydrodynamic modelling. The finite difference methods are common method 
for solving two-dimensional shallow water equations, in which the MacCormack scheme (W., 1969) is widely used for its low dissipation and the ability of capturing shock wave. But this scheme usually has numerical oscillation near the shock wave, thus need to introduce artificial dissipation. The named TVD (Total Variation Diminishing) dissipation method is used to improve Mac-Cormack scheme. The improved scheme has two steps: the prediction step and the correction step (Equation (3) and Equation (4), taking $\mathrm{X}$ direction as an example).

$$
\begin{aligned}
& X_{i}^{p}=X_{i}^{n}-\left(F_{i}^{n}-F_{i-1}^{n}\right) \cdot \Delta t / \Delta x+S^{n} \cdot \Delta t \\
& X_{i}^{c}=X_{i}^{n}-\left(F_{i+1}^{p}-F_{i}^{p}\right) \cdot \Delta t / \Delta x+S^{p} \cdot \Delta t
\end{aligned}
$$

The superscript " $p$ " means the prediction step; and the superscript " $c$ " means the correction step. The superscript " $n$ " represents the number of grid; and the subscript " $i$ " represents the index of time step. $\Delta t, \Delta x$ is time step and spatial resolution respectively. $F$ represents flux variable; and $S$ represents source variable. The TVD-MacCormack scheme can easily handle source items, and the whole scheme has two order accuracy in time and space, thus is better than other schemes (Liang D, 2007).

\section{Study area and datasets}

\subsection{Study area}

The model is applied in Xiamen Island, Fujian Province, China. Xiamen Island is very famous for it is the one of the most beautiful island in China. But it suffers from heavy rain and urban flooding in Summer. There are several typhoons land on the island every year, which lead to serious urban flood in some blocks of the city. The area of Xiamen Island is $141.09 \mathrm{~km}^{2}$. The mean annual precipitation is $1530 \mathrm{~mm}$, and it concentrates in summer. The monthly precipitation is up to $700 \mathrm{~mm}$ in some specific wet year. For instance, the precipitation in July of 1958 was $702 \mathrm{~mm}$, which is the highest monthly precipitation recorded.

\subsection{Rainfall data}

The storms usually have two peaks in Xiamen Island. Error! Reference source not found. shows the typical rain pattern of a 24 -hour event. The rain pattern is used to prepare rainfall input, based on rainfall records between 1985 2016 (supplied by local monitor stations). The daily precipitation of 50 -year return event is $335 \mathrm{~mm}$.

\subsection{Underlying surface}

The underlying surface in Xiamen Island is classified into four types according to its characteristics of permeation. The buildings and road are impermeable. The pavements and residential areas are usually semi-permeable following Sponge City guideline (Wang Hao, 2017). The green lands are permeable. Figure 2 shows the distribution of four types of underlying surface. According to the statistics, the impermeable surface is about $38 \%$, the semi-permeable surface is about $40 \%$, the permeable surface is about $19 \%$, and the water surface is about $3 \%$. 


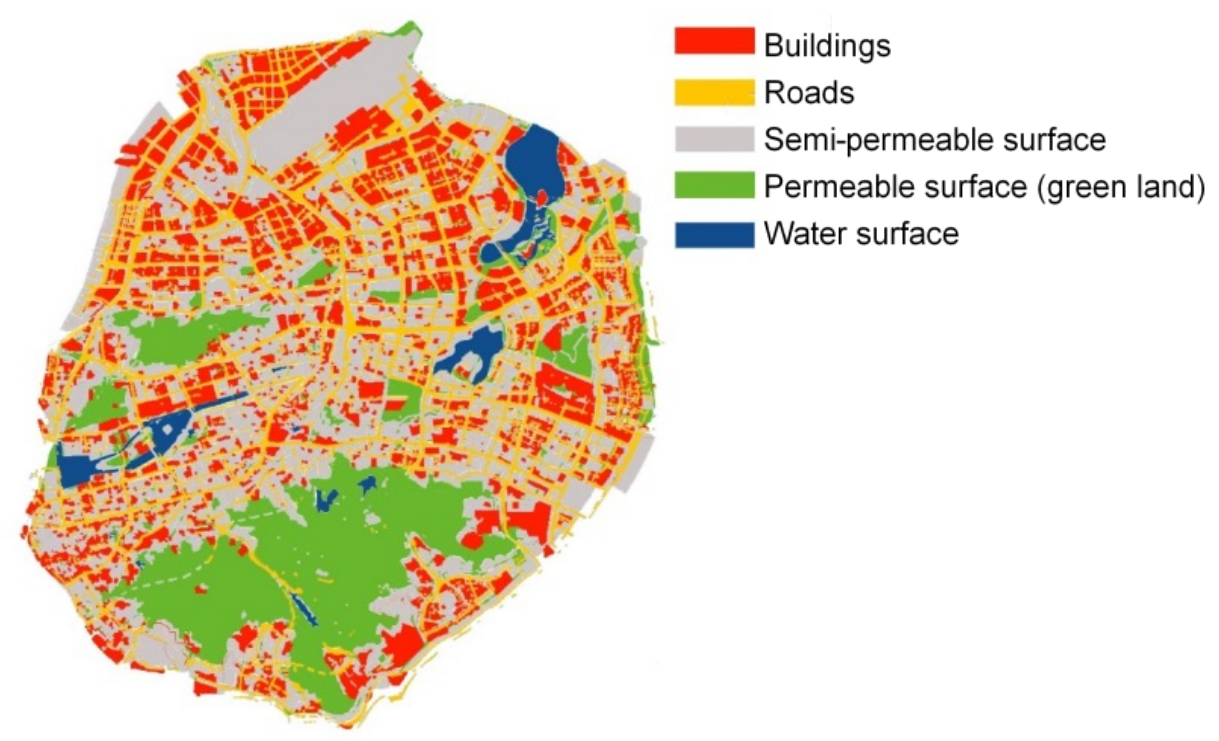

Figure 2: Map of underlying surface in Xiamen Island

\subsection{Terrain data}

The terrain data masked with buildings areas are used for runoff and flooding simulation over the land surface. Figure 3 shows the terrain and buildings in Xiamen Island.

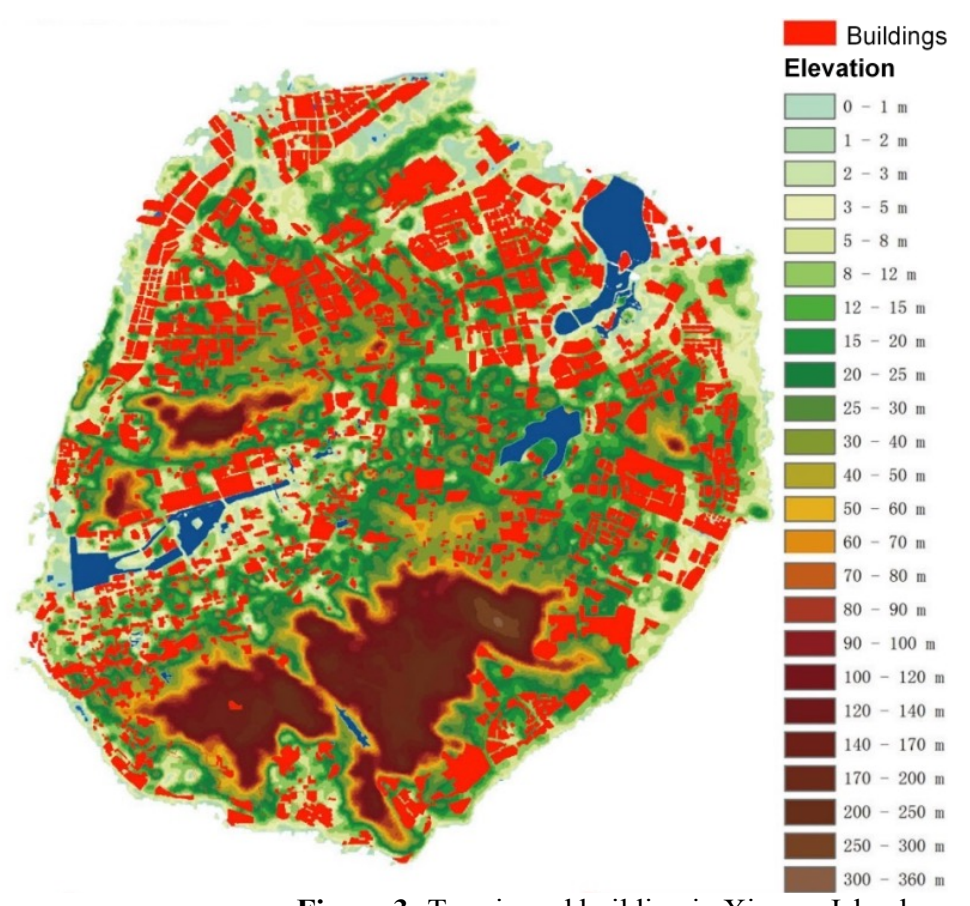

Figure 3: Terrain and building in Xiamen Island 


\section{Simulation and results}

The urban flooding was simulated based on the proposed model and the datasets mentioned above. The rainfall datasets were input to calculate the water yield for different underlying surfaces. Then the water yield on every grid was input to the hydrodynamic module step by step as source of water. The hydrodynamic module simulated the runoff and inundation processes based on the terrain grid and two-dimensional shallow water equation. In order to avoid numerical oscillations, the named Total Variation Diminishing (TVD) method is used to improve MacCormack finite difference scheme, which is a widely used scheme in fluid mechanics.

Figure 4 shows the distribution of the inundated areas in Xiamen Island under storm of 50-year event. The places of severe inundation (water depth $>0.4 \mathrm{~m}$ ) are located in three groups: the first group is to south east of the Yundang Lake; the second group is around the Hubian Reservoir; the third group is along the Exhibition Road. The point survey of urban flood was done by investigation and consulting flood records. The survey has identified 26 inundation areas in Xiamen Island (red points in Figure 4), which is consistent with the simulation results.

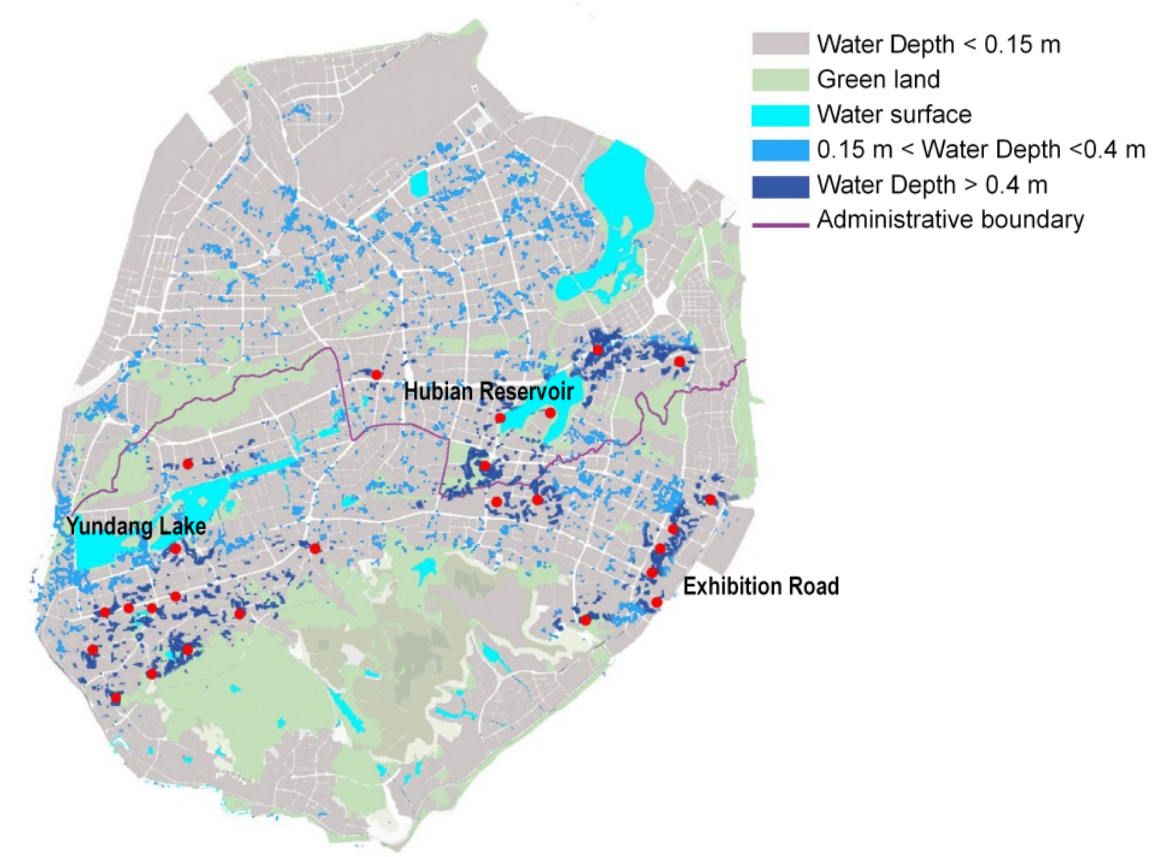

Figure 4: The distribution of inundated areas in Xiamen Island under storm of 50-year event

\section{Conclusion}

Urban flooding is becoming more and more severe under rapid urbanization in China. This paper proposed an integrated model based on hydrological processes and two-dimensional shallow water equation to simulate urban flooding. The TVD-MacCormack finite difference scheme is used for numerical calculation. The proposed model was applied in Xiamen Island. The inundation areas under storm of 50-year event have been simulated. The results are reasonable by compare with the point 
survey of urban flood, which implies that the proposed model is potentially useful for urban flood prediction.

\section{Acknowledgements}

This study was supported by the Chinese National Natural Science Foundation (No. 51522907 \& 51739011), the National Key Research and Development Program of China (2016YFC0401401), and the Research Fund of the State Key Laboratory of Simulation and Regulation of Water Cycle in River Basin, China Institute of Water Resources and Hydropower Research (No. 2017ZY02).

\section{References}

A. Kadari, S. R. Mekala, N. Wanger, D. Malan, J. Köth, K. Doll, et al (2011). Human contribution to more-intense precipitation extremes. Nature, 470(7334), 378-381.

Amaguchi H, Kawamura A, Olsson J, Takasaki T. (2012). Development and testing of a distributed urban storm runoff event model with a vector-based catchment delineation. Journal of Hydrology, (508): 240-253.

J. Zhang, X. Song, G Wang, H. Ruimin, X. Wang (2014). Development and challenges of urban hydrology in a changing environment: I: hydrological response to urbanization. Adcances in Water Science, 25(4), 594-605. (in Chinese).

J. Zhang, Y. Wang, H. Ruimin, H. Qingfang, X. Song. (2016). Discussion on the urban flood and waterlogging and causes analysis in China. Advances in Water Science, 27(4), 485-491. (in Chinese).

Jiahong Liu, Chenyao Xiang, Weiwei Shao, Yong Luan. (2016). Sponge City construction in Xiamen, China. Hydrolink, (4): 103-105.

Leandro J, Schumann A, Pfister A (2016). A step towards considering the spatial heterogeneity of urban key features in urban hydrology flood modelling. Journal of Hydrology, 535: 356-365.

Liang D, Lin B, Falconer R A (2007). Simulation of rapidly varying flow using an efficient TVDMacCormack scheme. International Journal for Numerical Methods in Fluids, 53(5): 811-826.

Liu Jiahong, Mei Chao, Xiang Chenyao, Shao Weiwei, Wang Hao and Yu Haijun, et al (2017). Principles of urban hydrological model. Water Resources and Hydropower Engineering, 48(5): 1-13. (in Chinese).

Liu Jiahong, Wang Hao, Gao Xuerui, Chen Silan, Wang Jiahua and Shao Weiwei (2014). Review on urban hydrology. Chinese Science Bulletin, 59(36): 3581-3590.

Montgomery M. R. (2008). The urban transformation of the developing world. Science, 319(5864): 761-764.

Ragab R, Bromley J, Rosier P, Cooper J D, and Gash J H C (2003). Experimental study of water fluxes in a residential area: 1. Rainfall, roof runoff and evaporation: he effect of slope and aspect. Hydrological Process, (17): 2409-2422.

Ramier D, Berthier E, and Andrieu H (2011). The hydrological behaviour of urban streets: longterm observations and modelling of runoff losses and rainfall-runoff transformation. Hydrological Process, (25): 2161-2178.

Smith B K, Smith J A, Baeck M L, Villarini G and Wright D B (2013). Spectrum of storm event hydrologic response in urban watersheds. Water Resources Research, 49(5): 2649-2663.

Thomas C W, Christine A P, Steven J B (2014). Hydrologic modeling analysis of a passive, residential rainwater harvesting program in an urbanized, semi-arid watershed. Journal of Hydrology, (420-421): 205-215. 
MacCormack R. W. (1969). The effect of viscosity in hypervelocity impact cratering. AIAA Paper, 69-354.

Wang Hao, Mei Chao, Liu Jiahong (2017). Systematic construction pattern of the Sponge City. Journal of Hydraulic Engineering, 48(9): 1009-1014. (in Chinese).

Zheng Z, G. J. (2016). Urban flooding in China: main causes and policy recommendations. Hydrological Process, 30(7): 1149-1152. 